\title{
Falsas variantes en las ediciones de textos*
}

\author{
Raïssa Kordic Riquelme ${ }^{* *}$ \\ Universidad de Chile
}

\section{INTRODUCCIÓN}

La filología latinoamericana de los últimos decenios ha ido asomándose tímidamente en los terrenos de la crítica textual, su más emblemática y representativa actividad. Esa timidez ha repercutido en ausencia de reflexión e innovación en la materia, tanto en lo que respecta a la edición de obras de época como a las modernas. Pareciera que este campo estuviera vetado para la mirada hispanoamericana, con escasas excepciones. Paralelamente a la ausencia de producción teórica, la edición de textos coloniales se ha centrado casi exclusivamente en las obras producidas en zonas virreinales, como México y Perú, dejando de lado la producción de las zonas política y culturalmente más periféricas en la época.

Cuando la filología latinoamericana (normalmente preocupada de temas hermenéuticos) se ha atrevido a entrar en materias ecdóticas ${ }^{1}$ o de crítica textual, en lo que a producción de ediciones se refiere, ocasionalmente lo ha hecho intentando seguir al pie de la letra, calcando, en todos sus aspectos, el

\footnotetext{
* Trabajo realizado para el Proyecto Fondecyt 1085189 y presentado con ocasión del congreso internacional GRISO (Grupo de Investigación Siglo de Oro, Universidad de Navarra) y Pontificia Universidad Católica sobre cautivos y cautiverios en la literatura colonial hispanoamericana, en Santiago de Chile, junio de 2009.

** Para correspondencia dirigirse a: Raïssa Kordic (rkordic@uchile.cl), Departamento de Lingüística, Facultad de Filosofía y Humanidades, Universidad de Chile, Av. Cap. Ignacio Carrera Pinto 1025, Tercer Piso, Nuñoa, Santiago.

1 Más detalles sobre el origen y uso del término en Orduna 2000: 6.
} 
método de la filología peninsular, poseedora de una tradición que en poco coincide, por ejemplo, con la chilena, por el tipo de producción textual y su historia específica cultural (Kordic 2006).

A continuación revisaremos, brevemente, dos conceptos que nublan el entrecejo editor chileno: testimonio y edición crítica.

\section{LA LEGITIMIDAD DEL TESTIMONIO}

Cuando se quiere realizar la edición crítica de una determinada obra de época y de tradición impresa (textos coloniales peruanos, mexicanos, españoles del siglo de oro, latinos, etc.) es necesario reunir los ejemplares que existan de esa obra y seleccionar aquellos que sean valiosos para la reconstrucción de su arquetipo, de su original, o para la reconstrucción de un texto ecléctico que refleje la intención del autor, según sea concebida la misión de una edición crítica.

Los ejemplares existentes, dicho de manera resumida, serán colacionados y estudiados y se realizará una selección de aquellos que por distintas razones técnicas, internas y externas, puedan ser considerados como poseedores de autoridad o valor técnico, y serán eliminados aquellos idénticos que no entreguen información diferenciable o valiosa para la reconstrucción, o que aporten con errores propios y exclusivos de una indudable copia de testimonio conservado (eliminatio codicum descriptorum). Los ejemplares seleccionados, no eliminables, ya no serán meros ejemplares o ediciones cualesquiera conservadas, sino que adquirirán el rango de testimonios, y serán la materia útil para elaborar la edición crítica.

\section{EL VALOR DEL TESTIMONIO}

Existe normalmente autoridad o valor muy variable de los eventuales testimonios: algunos pueden aportar con diferencias meramente gráficas, es decir, muy secundarias, y que se originan en los hábitos de distintos copistas. Probablemente hayamos optado por eliminarlos todos en el proceso anterior, tomando nota de todas las diferencias. Otros ejemplares 
mostrarán particularidades nacidas de los accidentes eventuales del plano impresor: obras mal encuadernadas que omiten o transmutan partes de su contenido, saltos de párrafos o líneas o capítulos enteros debido a errores humanos, problemas derivados del trabajo de cajistas que confunden el orden de las líneas, etc. Estos ejemplares pueden aportar a veces información de mayor interés para el establecimiento de la filiación de los testimonios conservados.

También la autoridad o valor de un testimonio puede variar según factores como el grado de determinación del autor en el resultado final de la obra, la intromisión indebida en el texto por parte de editores, etc.

Todo testimonio debe ser estudiado en sus aspectos internos y externos para determinar su confiabilidad y valor reconstructivo.

Un ejemplo edificante de lo compleja que puede resultar la ponderación de la autoridad de un testimonio, lo hallamos en el Manual de crítica textual (1983: 193) donde Alberto Blecua destaca, refiriéndose a los problemas de edición del teatro español de siglo XVI, el ejemplo de las farsas de Diego Sánchez de Badajoz: "aparecieron en edición póstuma al cuidado de su sobrino, que probablemente utilizó un autógrafo y copias manuscritas. Aunque el sobrino no interviniera en el texto, la edición hecha en mal papel, con tipos gastados y por un impresor de poco relieve, es poco de fiar, en especial en materia de grafías tan importantes para una obra en la que se utilizan numerosos dialectalismos y jergas".

Como podemos apreciar, incluso las ediciones de época pueden ser consideradas inconfiables y sin valor reconstructivo.

Las copias antiguas de una obra siempre son interesantes porque pueden aportar, por ejemplo, en el esclarecimiento de la lectura de pasajes perdidos o deteriorados, o con otras interpretaciones de puntos críticos, pero no son en ningún caso considerables como testimonios legítimos de la obra.

\section{LA IMPRENTA}

En la filología española hay una tradición de textos impresos desde finales del Medioevo (la imprenta llegó a España en 1472), y por tanto existen ediciones de obras de época hechas en vida del autor y poseedoras de valor reconstructivo, pero también existen ediciones que no poseen este valor por razones como la que hemos considerado en el ejemplo arriba citado. 
El estudio de los testimonios con autoridad (los realmente útiles) permitirá mediante el establecimiento de los errores comunes conjuntivos ${ }^{2}$ proponer la filiación y preparar, a partir de estas consideraciones, la edición crítica de la obra.

Queda entonces clara, con esta breve descripción panorámica, la distinción básica entre los conceptos de testimonio con valor reconstructivo y el de edición o mera publicación impresa de una obra o ejemplar.

Cabe la posibilidad de que en la tradición textual impresa, como la española, la mexicana, la peruana o la latina, una edición pueda también ser considerada como testimonio: por supuesto que sí, en caso de que se compruebe además su autoridad o valor reconstructivo.

\section{CHILE}

¿Pero, qué ocurre en una tradición como la chilena, manuscrita y de un solo testimonio?

Los únicos casos excepcionales en esta situación textual son los de Pedro de Oña y Alonso de Ercilla, publicados en el mismo siglo XVI, que además, por su origen en el caso de Ercilla (español y con mínima permanencia en tierras americanas), y por su formación en el caso de Oña (en el virreinato peruano, tanto la escolar como la universitaria), son los textos menos considerables, estética y lingüísticamente, como chilenos propiamente tales. Su influjo peninsular, mucho más refinado y formalizado, los aleja de la situación habitual en tierras chilenas de la Colonia, cuyos textos se caracterizan por una estética de emergencia, de un carácter fundamentalmente narrativo y descriptivo, realizados por soldados escritores autodidactas, que

2 Un ejemplo precioso de la capacidad filiativa de los errores comunes conjuntivos la hallamos en el Manual (Blecua 1983: 29), con el caso de las variantes balando, bailando, saltando (las ovejas) que traen distintos testimonios del Libro de Buen Amor. En términos sencillos y pedagógicos diremos que es claro que los testimonios que traen el verbo balar, por su condición más culta (lectio difficilior), corresponden a la lectura "original" de la que derivan las demás. Bailar es trivialización (lectio facilior) clara de balar, y con ella se agrupan los testimonios que traigan esta misma lectura como descendientes de los que traen balar. Y a su vez, los que traen saltar derivan, con esta innovación (corrección que hace el copista al absurdo de bailar), de la familia de los que estampan bailar.

Balar $>$ bailar $>$ saltar nos permite presumir un orden de descendencia o filiación entre los testimonios conservados de la obra. 
reflejan una lengua más arcaizante y vulgar. Incluso el caso de Francisco Núñez de Pineda, autor de Cautiverio feliz, formado en colegio jesuita chileno, exhibe la mayor parte de los rasgos propios, estéticos y lingüísticos, de la producción textual local.

Los problemas textuales de la tradición manuscrita, como bien nos recuerda Blecua (Manual: 202), son más complejos siempre que los que plantean los impresos.

\section{UN EJEMPLO PUNTUAL CHILENO}

Revisaremos el caso de la Crónica de Jerónimo de Vivar (s. XVI) en cuya edición me encuentro actualmente abocada:

De esta obra se conocían referencias desde Antonio de León Pinelo (1629), pero, como sabemos, se mantuvo extraviada hasta el siglo XX, en que se realizó su primera edición, la facsimilar de 1966.

La situación filológica de las ediciones existentes es la siguiente: la primera edición realizada es la referida edición facsimilar transcrita por Irving Leonard (1966). Leonard, como todos los paleógrafos, sin formación lingüística, desconoce los fenómenos idiomáticos de época, ignorándolos o adulterándolos gravemente. A raíz de ello, no solo tenemos un texto con severa tergiversación en el plano léxico, sino que también morfosintáctico $y$, en definitiva, del contenido del discurso.

Hay dos ediciones que fueron manifiestamente hechas para la divulgación general, y están resumidas y simplificadas: la de Ángel Barral Gómez (1988) y la de Sonia Pinto Vallejos (1987).

La más cuidada de todas las ediciones publicadas hasta hoy es la de Leopoldo Sáez-Godoy (1979), que citaremos como edición Verlag.

La edición Verlag, intentando calcar el método de la filología española, incurrió en la grave confusión de considerar la transcripción de Irving Leonard (la de 1966, criticada por este mismo editor en su prólogo por las múltiples erradas lecturas) como un testimonio con valor reconstructivo de la obra, y estableció un completo y detallado aparato de variantes al pie con las lecturas disímiles de esta edición hecha por el historiador en pleno siglo XX.

La mayoría de los textos chilenos coloniales tuvo sus primeras ediciones de manos de historiadores del siglo XIX, quienes legítimamente realizaron 
transcripciones de estas obras porque necesitaban fuentes para sus investigaciones historiográficas.

Es de una claridad absoluta el hecho de que estas ediciones historiográficas de siglo XIX no pueden ser consideradas como testimonios con valor reconstructivo de los textos coloniales que transcriben o editan. Pueden aportar, como todo trabajo investigativo, interesantes sugerencias de lecturas complejas, de solución de pasos obscuros culturales, históricos, etc., y ser citadas estas consideraciones y tenidas en cuenta al momento de hacer la edición crítica de la obra, pero no confundirse, bajo ninguna circunstancia, con testimonios con valor reconstructivo.

En Chile, la imprenta comienza a funcionar efectivamente a comienzos de siglo XIX. Por tanto, y por las razones antes señaladas, en la producción textual colonial chilena (casi en su totalidad manuscrita) los conceptos de edición y testimonio nunca son equivalentes.

\section{EL CONCEPTO DE EDICIÓN CRÍTICA}

Los principales conceptos de edición crítica actualmente aceptados son los siguientes ${ }^{3}$ :

1. "aquella que refleja de la manera más fiel las intenciones del escritor". Esta definición plantea problemas insolubles de tipo, incluso, metafísico como el interpretar la voluntad del autor.

2. Carol Bingham Kirby la definió como "la que reconstruye el arquetipo perdido, esto es, el texto del cual deben proceder todas las versiones existentes y la redacción más cercana al original del autor".

3. José María Ruano considera que edición crítica es "aquella que analiza de manera científica todas las relaciones textuales que existan entre los testimonios sobrevivientes con el objeto de producir un texto ecléctico que refleje en la medida de lo posible las intenciones finales del autor. Estas intenciones finales habrán quedado a veces

3 V. la página electrónica del GRISO sobre criterios editoriales. 
plasmadas en el manuscrito autógrafo, otras veces en un manuscrito copia, o en una edición impresa, o incluso en la conflación de varios testimonios". Concepto al que adherimos ya que nos parece de sumo interés entregar una visión lo más completa e informada de la obra.

Existiendo un único testimonio de la obra, como ocurre con la mayor parte de los textos de la producción colonial chilena, no cabría de manera estricta la posibilidad de hacer crítica textual ni ediciones críticas, pero como el conocimiento no consiste en la rígida aplicación de formatos únicos, aclaramos aquí que para el ejercicio ecdótico chileno, edición crítica ha de entenderse como sinónimo de texto filológicamente procesado, editado con criterios rigurosos y científicos acorde a la realidad y las necesidades de la producción local.

Como ya he señalado en otras partes, la producción textual colonial chilena está fuertemente caracterizada por su condición de pertenencia a una capitanía general, alejada del virreinato peruano, con una lengua española poco formalizada, en un contexto social donde no existían ni la imprenta (hasta finales del XVIII se imprimían únicamente naipes y esquelas), ni la educación universitaria laica (hasta s. XVIII).

Esta lengua española poco formalizada, más arcaica y vulgar, propia de la soldadesca o de los religiosos autodidactas, plantea el imperativo de un cuidadoso trabajo de anotación de fenómenos lingüísticos múltiples, fenómenos algunos de ellos que en la tradición española se han confundido con errores de copista (Kordic 2006).

Más que cautiverios, la ciencia plantea libertades. La creación rigurosa pero creativa del conocimiento y su materialización y otorgamiento de sentido en las diversas culturas es el desafío permanente para las ciencias humanas.

Está por cumplirse en estos días un año del fallecimiento de Mario Ferreccio, artífice de la crítica textual en Chile, a quien rindo homenaje. Su trabajo incansable e innovador inició en nuestro medio el interés y la conciencia americanista en torno a estos temas. 


\section{REFERENCIAS BIBLIOGRÁFICAS}

Barral Gómez, Ángel (editor). 1988. Crónica de los reinos de Chile. Madrid: Historia 16. Blecua, AlBerto. 1983. Manual de critica textual. Madrid: Castalia.

GRISO. Grupo de Investigación Siglo de Oro de la Universidad de Navarra [en línea]. Disponible en http://www.unav.es/griso/docs/lineas [Consulta 07/05/2010].

Kordic, RAïssa. 2006. La crítica textual hispanoamericana: algunas especificaciones metodológicas. Onomazein 13, pp. 191-202.

León Pinelo, Antonio De. 1629. Epítome de la Biblioteca Oriental y Occidental. Madrid: Juan González.

LEONARD, IRving. 1966. Crónica y relación copiosa y verdadera de los reynos de Chile (edición facsimilar). Santiago de Chile: Fondo Histórico y Bibliográfico José Toribio Medina.

Orduna, Germán. 2000. Ecdótica. Problemática de la edición de textos. Kassel: Edition Reichenberg.

Pinto Vallejos, Sonia (editora). 1987. Crónica y relación copiosa y verdadera de los reinos de Chile. Santiago de Chile: Universitaria.

SÁez-Godoy, Leopoldo (editor). 1979. Gerónimo de Vivar: Crónica y relación copiosa y verdadera de los reinos de Chile (1558). Berlín: Coloquium Verlag. 